\title{
Identification of MsHsp23 gene using annealing control primer system
}

\author{
Ki-Won Lee $\cdot$ Kyung-Hee Kim • Yong-Goo Kim • \\ Byung Hyun Lee $\cdot$ Sang-Hoon Lee
}

Received: 21 June 2011/Revised: 1 September 2011/ Accepted: 1 September 2011/Published online: 24 December 2011

(C) The Author(s) 2011. This article is published with open access at Springerlink.com

\begin{abstract}
To identify potential candidates for acquiring stress tolerance, a new annealing control primer (ACP) system was used to identify the differentially expressed genes. Alfalfa (Medicago sativa L.) seedlings were exposed to various abiotic stresses such as cold $\left(4^{\circ} \mathrm{C}\right.$ for $6 \mathrm{~h})$, heat $\left(42^{\circ} \mathrm{C}\right.$ for $\left.6 \mathrm{~h}\right)$, salt $(300 \mathrm{mM}$ for $6 \mathrm{~h})$, drought (withdrawing irrigation for $48 \mathrm{~h}$ ), copper $(500 \mu \mathrm{M}$ for $6 \mathrm{~h}$ ), cadmium $(500 \mu \mathrm{M}$ for $6 \mathrm{~h})$, and arsenic $(500 \mu \mathrm{M}$ for $6 \mathrm{~h})$. Primer sets 41 and 93 were differentially expressed and identified as same sequence, which represents a mitochondrial small heat-shock protein encoding gene, MsHsp23. This band was markedly increased or induced in alfalfa under heat, salt, and arsenic stresses. Differential expression of MsHsp23 was further evaluated by Northern blot analysis. Temporal expression analysis showed that mRNA pool was altered as early as $1 \mathrm{~h}$ of treatment. Thus, differential accumulation of $M s H s p 23$ under heat, salt, and arsenic stresses suggests its potential involvement in diverse abiotic stress tolerance, and thereby making a target for further molecular analysis.
\end{abstract}

Keywords Alfalfa A Annealing control primer - Abiotic stress $\cdot$ MsHsp23 $\cdot$ Medicago sativa

Communicated by Y. Wang.

K.-W. Lee · S.-H. Lee $(\square)$

Grassland and Forages Division, National Institute

of Animal Science, Rural Development Administration,

Cheonan 330-801, Korea

e-mail: sanghoon@korea.kr

K.-H. Kim · Y.-G. Kim · B. H. Lee

Division of Applied Life Science (BK21 Program),

Gyeongsang National University, Jinju 600-701, Korea

\section{Introduction}

Plants respond to diverse abiotic stresses such as cold, heat, drought, salinity, and heavy metals either individually or in combinations. The stresses caused by abiotic factors alter plant metabolism leading to negative effects on plant growth, development and productivity (Duncan and Carrow 2001). If the stress becomes harsh and/or continues for longer period, it may lead to unbearable metabolic burden on cells, reduce growth and ultimately result in plant death in extreme cases. A key to progress toward breeding better crops under stress has been to understand the changes in cellular and molecular machinery that occur in response to abiotic stress (Bowler et al. 1992; Noctor and Foyer 1998).

Modern molecular techniques involve the identification and use of molecular markers that can enhance plant breeding programs. For instance, superoxide dismutase and ascorbate peroxidase have been considered to be marker genes of responses to oxidative stress in plants (Foyer et al. 1994; Asada 1999). Alcohol dehydrogenase is one of the key genes identified in several studies that have been significantly induced in plants under oxygen depriving conditions (Sachs et al. 1980; Nanjo et al. 2011). A recent tissue specific proteomic analysis of soybean plants revealed that small heat shock protein (sHSPs) could be used as marker protein for heat stress (Ahsan et al. 2010). Thus identification of novel genes, which determine their expression patterns in response to stress and understanding their functions in stress adaptation, will provide the basis for engineering effective strategies to improve stress tolerance (Cushman and Bohnert 2000). Therefore, the development of genetically engineered plants by the overexpression of selected genes seems to be a viable option to hasten the breeding of "improved" plants. 
Intuitively, genetic engineering would be a faster way to insert beneficial genes than through conventional or molecular breeding (Wu et al. 2005; Hu et al. 2005). Also, it would be the only option when genes of interest originate from cross barrier species, distant relatives, or from nonplant sources. Indeed, there are several traits whose correlative association with resistance has been tested in transgenic plants. Following these logical steps, various transgenic technologies have been used to improve stress tolerance in plants (Allen et al. 1997).

To achieve this goal, a continuous effort for searching new 'important' genes is essential, which would contribute to stress tolerance in transgenic plants. Tolerance to abiotic stress may be achieved through the modification of endogenous plant pathways, often by manipulating important regulatory proteins such as transcription factors and molecular chaperons. Although genome sequencing technology has become progressively more efficient over the past decade, the sequencing of complex genomes remains expensive.

Several techniques are designed to identify differentially expressed genes (DEGs) in cells or tissues under various experimental conditions (Kim et al. 2004). It is also important in the case of abiotic stress tolerance to assess the effects and find out key gene(s) that contribute to stress tolerance. Here, we describe the annealing control primer (ACP)-based DEGs system to profile gene expression in alfalfa in responses to cold, heat, drought, salt and heavy metal stress.

\section{Materials and methods}

\section{Plant materials}

Alfalfa (Medicago sativa L. cv. Vernal) seeds were collected from Grassland and Forages Division, National Institute of Animal Science, Rural Development Administration, Cheonan, 330-801, Korea. After germination, seeds were planted in plastic pots containing Horticulture Nursery Medium (Biomedia, Korea) and grown in a growth chamber maintained at $25^{\circ} \mathrm{C}$ with a light intensity of $400 \mu \mathrm{mol} \mathrm{m}{ }^{-2} \mathrm{~s}^{-1}$ and 14-h photoperiod. Two-week-old seedlings were subjected to drought (withdrawing irrigation for $48 \mathrm{~h})$, heat $\left(42^{\circ} \mathrm{C}\right)$ cold $\left(4{ }^{\circ} \mathrm{C}\right)$, salt $(300 \mathrm{mM})$, copper $\left(\mathrm{CuSO}_{4}, 500 \mu \mathrm{M}\right)$, cadmium $\left(\mathrm{CdCl}_{2}, 500 \mu \mathrm{M}\right)$, and arsenic $\left(\mathrm{Na}_{2} \mathrm{HAsO}_{4} .7 \mathrm{H}_{2} \mathrm{O}, 500 \mu \mathrm{M}\right)$. For heat and cold treatments, seedlings were transferred into a growth chamber and exposed for $6 \mathrm{~h}$ whereas in case of salt and heavy metal treatments, seedlings were watering with mentioned concentration of the salt and chemicals and exposed for $6 \mathrm{~h}$. After each treatments, leaves were harvested separately, frozen by liquid nitrogen and were kept at $-80^{\circ} \mathrm{C}$ until use.

RNA was isolation and ACP-based PCR

Total RNA was isolated from the leaf tissues of treated and control plants using the Plant RNeasy mini kit (Qiagen, CA, USA) and using the GeneFishing ${ }^{\text {TM }}$ DEG kit (Seegene, Seoul, South Korea), DEGs were identified by an ACP-based PCR method as described by Lee et al. (2009).

Sequence analysis

Selected DEGs were extracted from the gel using the GENCLEAN II Kit (Q-BIO gene, Carlsbad, CA, USA) and directly cloned into a TOPO TA cloning vector (Invitrogen, Carlsbad, CA, USA) according to the manufacturer's instructions. The cloned plasmids were sequenced with an ABI PRISM 3100 Genetic Analyzer (Applied Biosystems, Foster City, CA, USA) using the M13 forward primer (5'-CGCCAGGGTTTTCCCAGTCACGA-3') or M13 reverse primer $\left(5^{\prime}\right.$-AGCGGATAACAATTTCACACAGGA-3'). Sequencing data were confirmed with the GenBank database through the Blastx program of NCBI (http://www.ncbi.nlm. nih.gov/BLAST/).

Expression analysis of $\mathrm{MsHsp23}$

Northern blot analysis was carried out to investigate the temporal expression of MsHsp23 gene in response to various abiotic stresses. Northern blot analysis was performed as described previously (Lee et al. 2007).

\section{Results and discussion}

\section{Identification of $M s H s p 23$ gene}

To identify differentially expressed genes under high or low temperatures, salinity, drought and heavy metals, ACP-based GeneFishing PCR technology was used with a combination of 120 arbitrary primers. Out of 120 ACP primers, ACP 93 and ACP 41 showed differentially expressed DNA bands under heat, salt and As. The bands size was about $1 \mathrm{~kb}$ (Fig. 1). The DNA bands were identified as same sequence, which represents a mitochondrial small heat-shock protein coding gene, MsHsp23 (Fig. 1). This band was increased in alfalfa under heat, salt and As stresses and it suggests that MsHsp23 may involved in those stresses. It has been reported that small heat-shock proteins are usually undetectable in vegetative tissue under normal growth conditions, but can be induced by 
Fig. 1 Agarose gel electrophoresis shows results of annealing control primer system for the identification of DEGs in response to various abiotic stresses indicated. $N$ control; $C$ cold; $H$ heat; $S$ salt; $D$ drought; $C u$ copper; $C d$ cadmium and $A s$ arsenic. Arrows indicating the induction of the gene under the following stresses. ACP indicates the set of primers used for each PCR reaction. The expression of small HSP was increased under heat $(\mathrm{H})$, salt $(\mathrm{S})$ and As stress
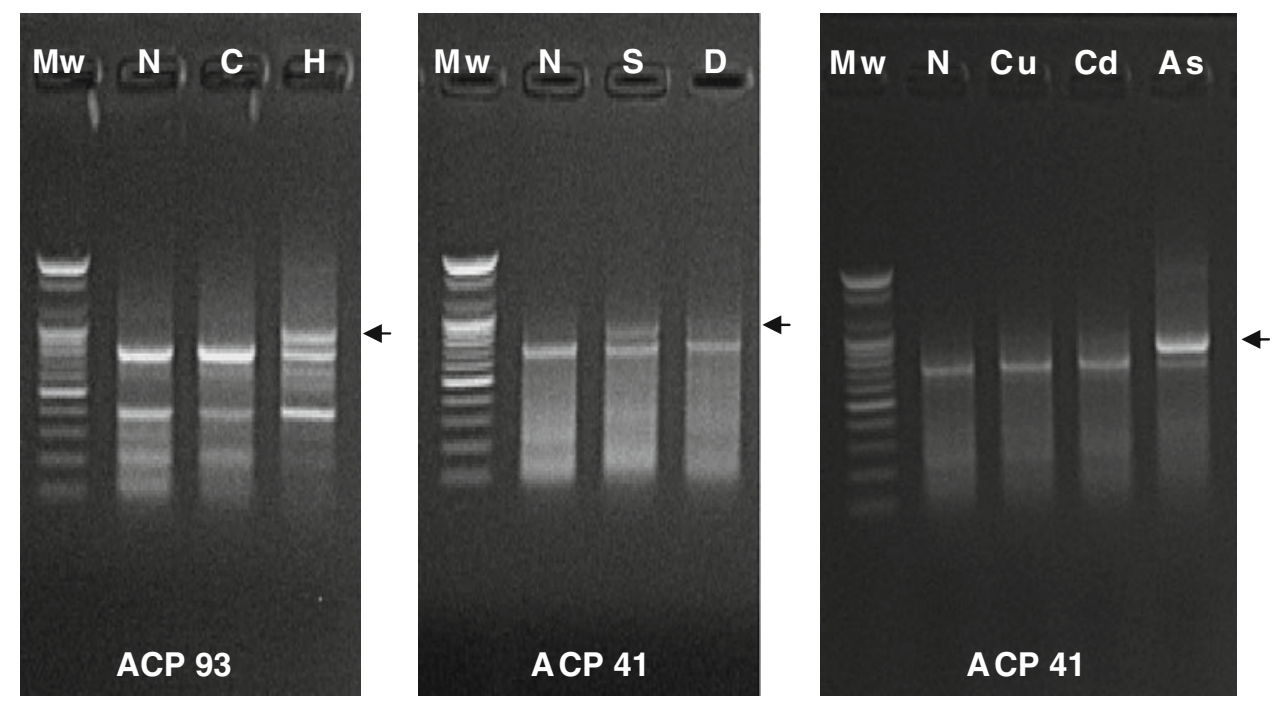

developmental stimuli or by environmental stresses including heat (Sun et al. 2002; Lee et al. 2007).

Sequencing of the MsHsp23

The full-length cDNA of the MsHsp23 gene had a size of 863 bp with $5^{\prime}$ - and $3^{\prime}$-untranslated regions (UTRs) and a polyA tail. The open reading frame (ORF) was flanked by a 198-bp 5'-UTR and a 32-bp 3'-UTR. An ORF search showed that $M s H s p 23$ contained a 633-bp ORF encoding a protein with 213 amino acids (Fig. 2). The calculated molecular weight of the encoded protein was approximately $23.36 \mathrm{kDa}$, with a theoretical isoelectric point of 5.246 .
Expression of the MsHsp23 gene under various abiotic stresses

To investigate the temporal mRNA expression patterns of MsHsp23, northern blot analysis was carried out. As shown in Fig. 3, results of a northern blot analysis were virtually consistent with that of the ACP-based RT-PCR with minor discrepancies. To confirm more clearly, heat, salt or As stresses cause high accumulation of MsHsp23 transcripts, while it was reduced under cold stress. In case of drought stress, the expression difference is not detectable. Above all, the ACP technique allowed the isolation of differentially expressed genes under the conditions tested. Our results clearly indicate that the differential accumulation
Fig. 2 Nucleotide and deduced amino acid sequences of alfalfa small Hsp23. Numbers at the right indicate nucleotide and amino acid position. The untranslated regions of $5^{\prime}$ and $3^{\prime}$ of $M s H s p 23$ are denoted by italic. The mitochondrial targeting signal peptides and their cleavage site are shown as red line and arrow, respectively. The alpha-crystalline domain is underlined (blue)

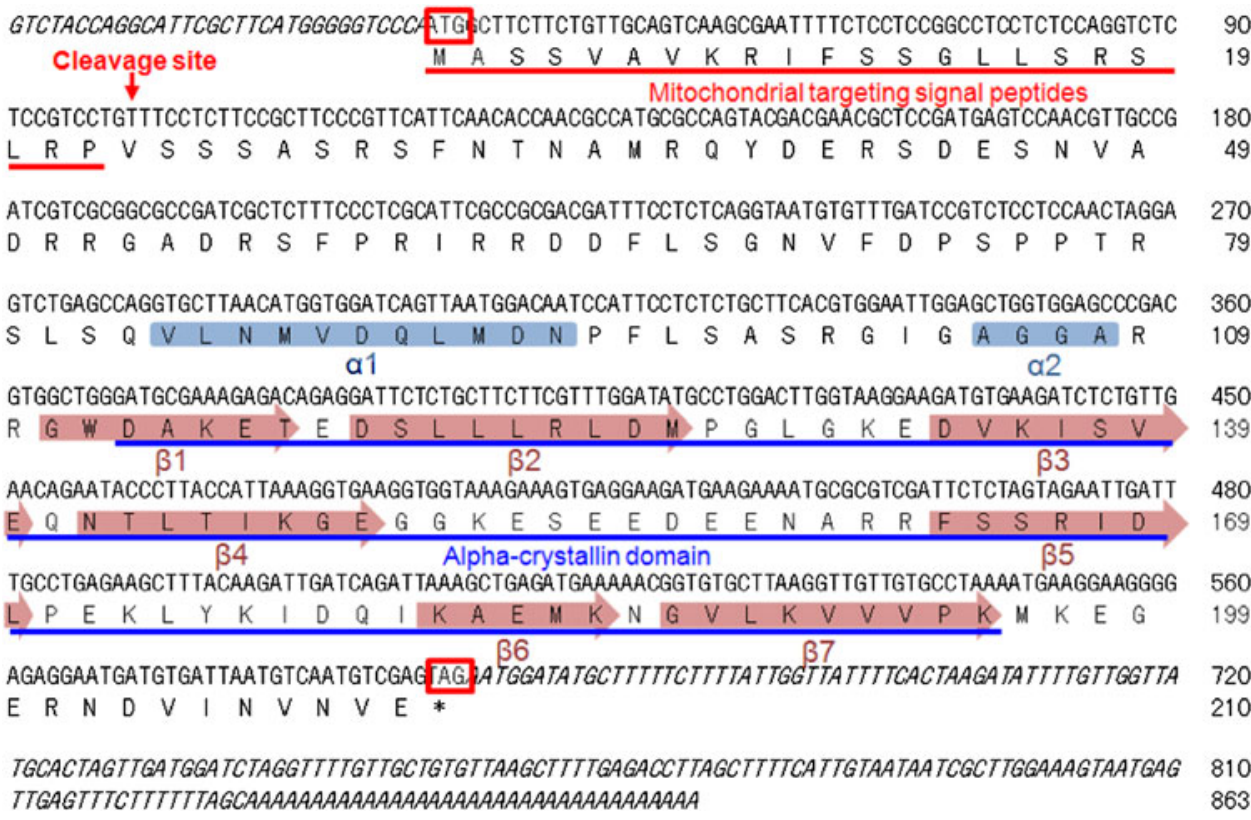


Fig. 3 Expression levels of the $M s H s p 23$ gene under various abiotic stresses. The treated alfalfa seedlings were harvested at the indicated times

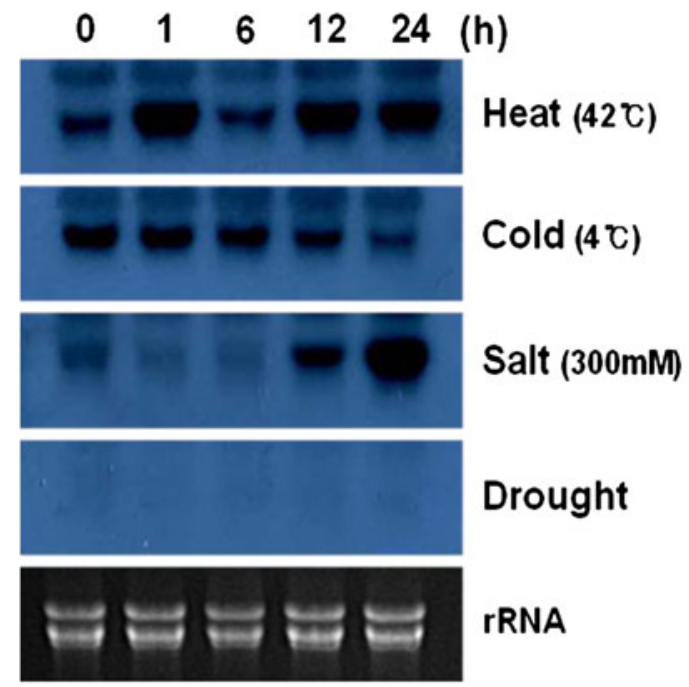

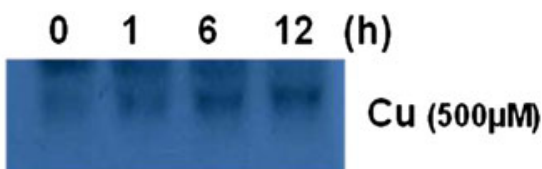

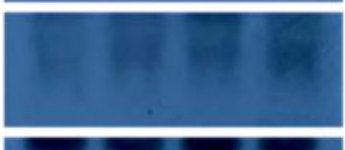

$\mathrm{Cd}(500 \mu \mathrm{M})$

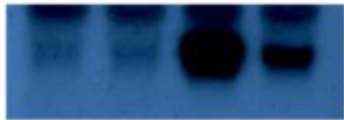

As $(500 \mu \mathrm{M})$

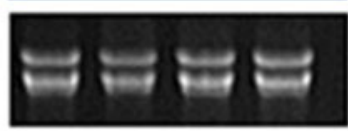

rRNA patterns of MsHsp33 transcripts were observed by the different stress treatment, and it shows the possibility of which MsHsp23 may be involved in diverse stress conditions and confer the stress tolerance. It has been reported in several studies that in addition to heat stress, plant sHSPs are also accumulate in response to a large number of other stresses such as heavy metals, oxidative stress and salt conditions (Wang et al. 2003; Ahsan et al. 2007; Sarkar et al. 2009). Moreover, Yeh et al. (2002) also reported that the overexpression of sHSPs in E. coli showed enhance thermotolerance, as well as changes in the protein aggregation patterns.

The molecular responses to various abiotic stresses were investigated by the approaches with transcriptomic analysis based on an ACP system. Here we identified differentially expressed genes under abiotic stresses in alfalfa seedlings and they were mostly unknown genes and a few common stress-related genes (data not shown). Among them, mitochondrial small Hsp23, MsHsp23, was responded by the diverse stress treatment such as heat, salt, As stresses and thus it could be a strong candidate that may confer the abiotic stress tolerance to plants.

Acknowledgments This study was supported by 2012 Post Doctoral Course Program of National Institute of Animal Science, Rural Development Administration, Republic of Korea.

Open Access This article is distributed under the terms of the Creative Commons Attribution Noncommercial License which permits any noncommercial use, distribution, and reproduction in any medium, provided the original author(s) and source are credited.

\section{References}

Ahsan N, Lee DG, Lee SH, Kang KY, Lee JJ, Kim PJ, Yoon HS, Kim JS, Lee BH (2007) Excess copper induced physiological and proteomic changes in germinating rice seeds. Chemosphere 67:1182-1193
Ahsan N, Donnart T, Nouri MZ, Komatsu S (2010) Tissue-specific defense and thermo-adaptive mechanisms of soybean seedlings under heat stress revealed by proteomic approach. J Proteome Res 9:4189-4204

Allen RD, Webb RP, Schake SA (1997) Use of transgenic plants to study antioxidant defenses. Free Radic Biol Med 27:473-479

Asada K (1999) The water-water cycle in chloroplasts: scavenging of active oxygens and dissipation of excess photons. Annu Rev Plant Physiol Plant Mol Biol 50:601-639

Bowler C, van Montagu M, Inze D (1992) Superoxide dismutase and stress tolerance. Annu Rev Plant Physiol Plant Mol Biol 43:83-116

Cho K, Shibato J, Agrawal GK, Jung YH, Kubo A, Jwa NS, Tamogami S, Satoh K, Kikuchi S, Higashi T, Kimura S, Saji H, Tanaka Y, Iwahashi H, Masuo Y, Rakwal R (2008) Integrated transcriptomics, proteomics, and metabolomics analyses to survey ozone responses in the leaves of rice seedling. J Proteome Res 7:2471-2489

Cushman JC, Bohnert H (2000) Genomic approaches to plant stress tolerance. Curr Opin Plant Biol 3:117-124

Duncan RR, Carrow RN (2001) Molecular breeding for tolerance to abiotic/edaphic stresses in forage and turf grass. In: Spangenberg $\mathrm{G}$ (ed) Molecular breeding of forage crops. Kluwer Academic Publishers, Dordrecht, pp 251-260

Foyer CH, Descourvierse P, Kunert KJ (1994) Protection against oxygen radicals: an important defense mechanism studied in transgenic plants. Plant Cell Environ 17:507-523

Hu Y, Jia W, Wang J, Zhang Y, Yang L, Lin Z (2005) Transgenic tall fescue containing the Agrobacterium tumefaciens ipt gene shows enhanced cold tolerance. Plant Cell Rep 23:705-709

Kim YJ, Kwak CI, Gu YY, Hwang IT, Chun JY (2004) Annealing control primer system for identification of differentially expressed genes on agarose gels. Biotechniques 36:424-426

Lee DG, Ahsan N, Lee SH, Kang KY, Bahk JD, Lee IJ, Lee BH (2007) A proteomic approach in analyzing heat-responsive proteins in rice leaves. Proteomics 7:3369-3383

Lee S-H, Lee K-W, Kim K-Y, Choi GJ, Yoon SH, Ji HC, Seo S, Lim YC, Ahsan N (2009) Identification of salt-stress induced differentially expressed genes in barley leaves using the annealing control-primer-based GeneFishing technique. Afr J Biotechnol 8:1326-1331

Nanjo Y, Maruyama K, Yasue H, Yamaguchi-Shinozaki K, Shinozaki K, Komatsu S (2011) Transcriptional responses to flooding stress in roots including hypocotyl of soybean seedlings. Plant Mol Biol. doi:10.1007/s11103-011-9799-4 
Noctor G, Foyer CH (1998) Ascorbate and glutathione: keeping active oxygen under control. Annu Rev Plant Physiol Plant Mol Biol 49:249-279

Sachs MM, Feeling M, Okimoto R (1980) The anaerobic proteins of maize. Cell 20:761-767

Sarkar NK, Kim YK, Grover A (2009) Rice sHsp genes: genomic organization and expression profiling under stress and development. BMC Genomics 10:393

Sun W, Van Montagu M, Verbruggen N (2002) Small heat shock proteins and stress tolerance in plants. Biochim Biophys Acta 1577:1-9
Wang W, Vinocur B, Altman A (2003) Plant responses to drought, salinity and extreme temperatures: towards genetic engineering for stress tolerance. Planta 218:1-14

Wu YY, Chen QJ, Chen M, Chen J, Wang XC (2005) Salt-tolerant transgenic perennial ryegrass (Lolium perenne L.) obtained by Agrobacterium tumefaciens-mediated transformation of the vacuolar $\mathrm{Na}^{+} / \mathrm{H}^{+}$antiporter gene. Plant Sci 169:65-73

Yeh CH, Chen YM, Lin CY (2002) Functional regions of rice heat shock protein, Oshsp16.9, required for conferring thermotolerance in Escherichia coli. Plant Physiol 168:661-668 